\title{
Vulcanization, centrifugation, water-washing, and polymeric covering processes to optimize natural rubber membranes applied to microfluidic devices
}

\author{
Flávio C. Cabrera ${ }^{1}$ Guilherme Dognani ${ }^{1} \cdot$ Fabricio L. Faita $^{5} \cdot$ Renivaldo J. dos Santos $^{4}$ • \\ Deuber L. S. Agostini ${ }^{1}$ - Ivan H. Bechtold ${ }^{2}$ - Frank N. Crespilho ${ }^{3}$ • \\ Aldo E. Job ${ }^{1}$
}

Received: 20 August 2015/Accepted: 19 November 2015/Published online: 30 November 2015

(C) Springer Science+Business Media New York 2015

\begin{abstract}
Natural rubber microfluidic devices are based on the replication of microchannels and chambers through the casting of latex and combine the flexibility and transparency of the polymeric platform. Natural rubber is a proposed alternative material to prepare microfluidic devices, owing to the advantages of flexibility, ecofriendliness, and lower cost compared to other commonly used polymeric microfluidic materials. However, the challenges for the use of natural rubber are the leaching of compounds when it is in contact with fluids, the low stretching resistance, and the decreases of transparency rate in terms of the water absorption rate. To overcome these issues, we report the evaluation of the essential mechanical, optical, and structural properties of natural rubber for centrifuged and pre-vulcanized rubber membranes, as well as the polymeric coating over the membrane surfaces. We propose the centrifugation process for decreasing the leach
\end{abstract}

Electronic supplementary material The online version of this article (doi:10.1007/s10853-015-9611-y) contains supplementary material, which is available to authorized users.

Aldo E. Job

job@fct.unesp.br

1 Departamento de Física, Química e Biologia, Faculdade de Ciências e Tecnologia FCT/UNESP, Presidente Prudente, SP 19060-900, Brazil

2 Departamento de Física, Universidade Federal de Santa Catarina, Florianópolis, SC 88040-900, Brazil

3 Instituto de Química, Universidade de São Paulo, São Carlos, SP, Brazil

4 Universidade Estadual Paulista, Campus Experimental de Rosana, SP, Brazil

5 Centre of Physics, University of Minho, Campus de Gualtar, 4710-057 Braga, Portugal composition of the natural rubber platform and vulcanization to improve the mechanical resistance of the polymeric membrane devices. The polymeric coating prevents the leaching of compounds from natural rubber membranes and water absorption without significant reduction in transparency or increase in the hydrophobicity of the surface. Once the centrifuging, vulcanization, and coating processes improve the rubber properties, this polymer will become an alternative flexible and low-cost material for microfluidic technology.

\section{Introduction}

Natural rubber (NR) has attracted growing interest as a strategic material in the development of nanocomposites used as gas barriers [1], shape memory polymers based on temperature stimuli [2] or environmental gas recognition $[3,4]$, polymeric bactericide composites based on quaternary phosphonium salts [5] and silver nanoparticles [6], and thermomechanical actuators [7].

Improvements in the mechanical properties and environmental degradation resistance of NR by vulcanization have been well studied [8,9]. Furthermore, researchers are shifting their attention toward processes to decrease the leaching of protein compounds from latex [10] as a result of the current increase in latex allergy cases and consequent increase in interest regarding the evaluation of allergen agents $[11,12]$. Centrifugation has been reported as a clever approach for decreasing the amount of protein from the natural latex, thus decreasing allergy responses [10].

We have recently introduced the design concept of natural rubber-based microfluidic devices (NRMDs) for 
optical and electrochemical applications [13] and implemented a microreactor for the synthesis of decorated $\mathrm{Fe}_{3} \mathrm{O}_{4}$-AuNPs [14].

Several polymeric materials have been used to prepare device platforms, for instance, polystyrene (PS) [15], cyclic olefin copolymer (COC) [16], polymethamethylacrylate (PMMA) [17], poly(dimethylsiloxane) (PDMS) [18-20], and polyurethane methacrylate (PUMA) [21]. Nevertheless, PDMS has been identified as a highly promising candidate due to its transparency, flexibility, chemical resistance, hydrophobicity, and nontoxic properties. It has been the subject of numerous scientific works regarding point-of-care diagnosis applications [22], cell-based sensors for toxicants identified in water [23], immunoassays [24], enzymatic assays [25], DNA recognition [18], flowstretch chips as a model for simulating the hemodynamic microenvironment [26], and biofuel cells [19].

However, the hydrophobicity of PDMS is a disadvantage for biological applications and chemical synthesis. The use of natural rubber is a proposed alternative material to prepare microfluidic devices, owing to the advantages of greater flexibility, renewability, and low cost when compared to other commonly used microfluidic materials. Furthermore, natural rubber has a lower contact angle than PDMS and allows to form a polymeric cover layer on its surface.

Herein, we optimize the mechanical and structural properties of natural rubber membranes to implement them in microfluidic device construction. In addition, we evaluate the pre-vulcanization process as a method to improve the mechanical resistance of the polymeric platform and allow the vulcanization to be performed at lower temperatures and shorter times compared to the typical vulcanization process. The centrifuging process was used to improve the optical properties and decrease the leaching from natural rubber-based membranes. Polymeric layers of polyvinyl chloride (PVC) are also proposed as an internal barrier against the leaching of organic compounds from NR without increasing the surface contact angle.

\section{Materials and methods}

Self-standing natural-rubber membranes were prepared using latex collected from different rubber trees (Hevea brasiliensis) of the RRIM 600 clone. After extraction, latex samples were stabilized with ammonium hydroxide $(2 \% \mathrm{v} / \mathrm{v})$. In order to generate a comparative status of different types of latex, we used pre-vulcanized (industrial) $\left(\mathrm{NR}_{\text {Vulc }}\right)$ and centrifuged latex $\left(\mathrm{NR}_{\mathrm{Wat}}^{\mathrm{C}}\right)$ to prepare rubber membranes. The pre-vulcanized latex was acquired from Dulatéx Ltda. Industry. The protocol regarding the composition (Table $\mathrm{S} 1$ in the supporting information) of vulcanization agents and the pre-vulcanization process are presented in the supporting information. The latex was centrifuged to decrease the protein composition and to evaluate its influence on the optical properties of NR. The NR membranes produced from centrifuged latex $\left(N_{\text {Wat }}^{C}\right)$ were prepared using a rubber cream phase dissolved in Milli-Q water, which was obtained by submitting the InNature latex to centrifugation in a Cientec-CT 5000R centrifuge at $6000 \mathrm{rpm}$ at $4{ }^{\circ} \mathrm{C}$ for $90 \mathrm{~min}$. The NR and vulcanized natural rubber $\left(\mathrm{NR}_{\text {vulc. }}\right)$ membranes were prepared by the casting method with $10.0 \mathrm{~mL}$ of latex on Petri dishes (90 $\mathrm{mm}$ in diameter), followed by annealing at $65{ }^{\circ} \mathrm{C}$ (oven from FANEM $^{\circledR}$ company, 520 model) to obtain totally dried rubber membranes, i.e., around $15 \mathrm{~h}$ for $\mathrm{NR}$ and $5 \mathrm{~h}$ for $\mathrm{NR}_{\mathrm{vulc}}$. In the second stage, the preparation method for $\mathrm{NR}_{\mathrm{Wat}}^{\mathrm{C}}$ membranes was similar to that used to prepare the $\mathrm{NR}$ and $\mathrm{NR}_{\mathrm{vulc}}$ membranes, but with thermal annealing at $55{ }^{\circ} \mathrm{C}$ for $10 \mathrm{~h}$, as previously determined [27] The concentration of the cream phase (latex) aqueous solution used to prepare the $\mathrm{NR}_{\text {Wat }}^{\mathrm{C}}$ membranes was $400 \mathrm{mg} \mathrm{mL}^{-1}$.

Poly(vinyl chloride) (PVC) was acquired as a colorless liquid commercial adhesive based on PVC resin. PVC film was used to cover the natural rubber surface (NR/PVC) to prevent the leaching from the membranes and water absorption. The PVC covering procedure has been implemented to cover the internal surfaces of channels and chambers of rubber-based microfluidic devices, as previously reported [13, 14]. The PVC liquid was manually dropped over the rubber membrane surface, reaching thickness of around $18.0 \mu \mathrm{m}$. After PVC solvent evaporation, a polymeric layer obtained, which presents well adherence over NR surface. PDMS membranes were prepared using Sylgard 184 silicone elastomer, which was acquired from Dow Corning Corporation, USA. Ten (10.0) parts of pre-polymer base were mixed with 1.0 part of elastomer curing agent and annealed at $65{ }^{\circ} \mathrm{C}$ for $3 \mathrm{~h}$ to cure.

The mechanical, optical, morphological, and wettability properties were evaluated, and the leached compounds from elastomeric membrane samples were investigated to determine the best membranes for application in microfluidic devices. The samples were evaluated by stress-strain tests, in which they were stretched at a rate of $500 \mathrm{~mm} \mathrm{~min}^{-1}$ using an EMIC DL2000 digital universal testing machine coupled to an internal deformation transducer. The sample preparation was carried out according to ASTM D412, sample type C [28]. The surface morphology of the membranes was investigated by atomic force microscopy (AFM). The AFM images were collected using a digital instrument model Nanoscope IV with a silicon nitride tip and a spring constant of $0.12 \mathrm{~N} / \mathrm{m}$. 
Optical analyses were performed using visible-light absorption spectra obtained in transmittance mode using a Jasco V-670 spectrophotometer (deuterium-halogen light sources) at a scan rate of $400 \mathrm{~nm} \mathrm{~min}{ }^{-1}$. Static contact angle (sessile droplet) measurements were performed using a contact angle meter (DM300, Kyowa Interface Science Co.-Japan). Milli-Q water (distilled and deionized water) was used as the test liquid with a nominal droplet volume of $3 \mu \mathrm{L}$. Images of the drops were recorded with a microscope equipped with a CCD camera, and the shape and the contact angles were analyzed by Image- ${ }^{\circledR}$ software.

To evaluate the compounds leached from NR, the membranes were immersed in aqueous solutions to evaluate the compounds released from the polymeric support using around $790.0 \mathrm{mg}$ of material immersed in $100.0 \mathrm{~mL}$ of Milli-Q ultrapure water for $5 \mathrm{~h}$ at $40{ }^{\circ} \mathrm{C}$. The temperature was selected according to the extreme conditions reached in the human body during a fever state to demonstrate whether NR would release compounds into solution that are dangerous to the immunological system. The procedure is accepted based on NR biocompatibility [29, 30], allowing future implementation of rubber-based microfluidic devices as implanted sensors.

The solution of lixiviated compounds from rubber membranes, i.e., those obtained from NR (Ls-NR), NR prepared from centrifuged latex (Ls-NR $\mathrm{W}_{\mathrm{Wat}}^{\mathrm{C}}$ ), vulcanized NR (Ls-NR Vulc $)$, and a NR membrane totally covered by a PVC layer (Ls-NR/PVC) were evaluated by atomic mass spectroscopy with a Perkin Elmer model Optima 8000 spectrometer. The analytical curve was limited between 0.05 and $2.00 \mathrm{mg} / \mathrm{L}$ using ISO 34 patterns as a guide. Moreover, UV-Vis spectroscopy was implemented to complement the study of the released compounds. UV-Vis plasmon absorption data were obtained using a Varian spectrophotometer, model Cary 50, from 190 to $800 \mathrm{~nm}$ at a scan rate $600 \mathrm{~nm} \mathrm{~min}^{-1}$. The compounds released from rubber membranes into water were lyophilized for infrared spectroscopy with Fourier-transformed (FT-IR) analysis, in ATR (attenuated total reflectance) mode, which was recorded using a Bruker model Vetor 22 DTGS detector with 128 scans in the range of $600-4000 \mathrm{~cm}^{-1}$ with a resolution of $4 \mathrm{~cm}^{-1}$.

\section{Results and discussion}

\section{Device preparation}

The NR-based microfluidic device is shown in Fig. 1b. Its flexibility was demonstrated, despite the yellowed color of the membranes, where the transparency increased with decreasing thickness. The entire protocol for the manipulation of NR can be found in our previous report [14]. In summary, after the preparation of the molds, the template was covered with latex from Hevea brasiliensis trees (Fig. 1a) that was dropped on them, and the templates were then annealed for drying. Afterward, the NR membranes were manually removed from the molding templates to replicate the open chamber and channels as represented in the schematic diagram (Fig. 1d). The chamber had a thickness of around $0.7 \mathrm{~mm}$ (Fig. 1e). The PVC polymeric cover was deposited over the internal surfaces of the channels and chamber with a thickness of around $17.6 \mu \mathrm{m}$ (Fig. 1c). Finally, the microfluidic device was assembled by applying pressure manually, using the latex as an adhesive. Spiral channels have been proposed as a mixer for different fluids injected through inlet ports (Fig. 1e).

\section{Platform mechanical properties}

Stress-strain tests were carried out according ASTM D412 (Fig. 2) to evaluate the mechanical properties of NR membranes implemented as platforms for microfluidic device preparation.

Figure 2 (inset) shows the stress-strain curve characteristics of elastomers. The first step in the stretching process $(\alpha)$ indicates elastic deformation, i.e., the material can recover its original size after application of the investigated force. Moreover, the linear region of the stress-strain curve $(\beta)$ is attributed to the polymeric chain outflow and reaches the plastic deformation region (in the region of exponential increasing), which is the region before the rupture tension, where the force implemented produces a permanent deformation (highlighted for the $\mathrm{NR}_{\text {Vulc }}$ and PDMS membranes). The Young's modulus (E) and Poisson's ratio $(\mu)$ are calculated in Eq. 1:

$E=\frac{\alpha}{\varepsilon}$

Here, " $\alpha$ " is the tension stress measured at the maximum deformation (length "l") in the linear region of plastic deformation (Fig. 2b). The deformation, $\varepsilon$, is calculated according to Eq. 2:

$\varepsilon=\frac{l-l_{0}}{l_{0}}$

Here, $l_{0}$ is the sample initial length.

The equation for the Poisson's ratio $(\mu)$ is given in Eq. 3:

$\mu=\frac{1}{2}-\frac{1}{6}\left(\frac{E}{K}\right)$

where $E$ is the Young's modulus, and $K$ is the bulk modulus: 
Fig. 1 a Latex obtained from Hevea brasiliensis trees. b NRbased microfluidic device. c PVC layer $(17.6 \mu \mathrm{m})$ covering the NR surface (cross-sectional analysis). d Schematic diagram of the two-layered microfluidic device. e The spiral channels used to mix the injected fluids connected to the chamber used to analyze the samples
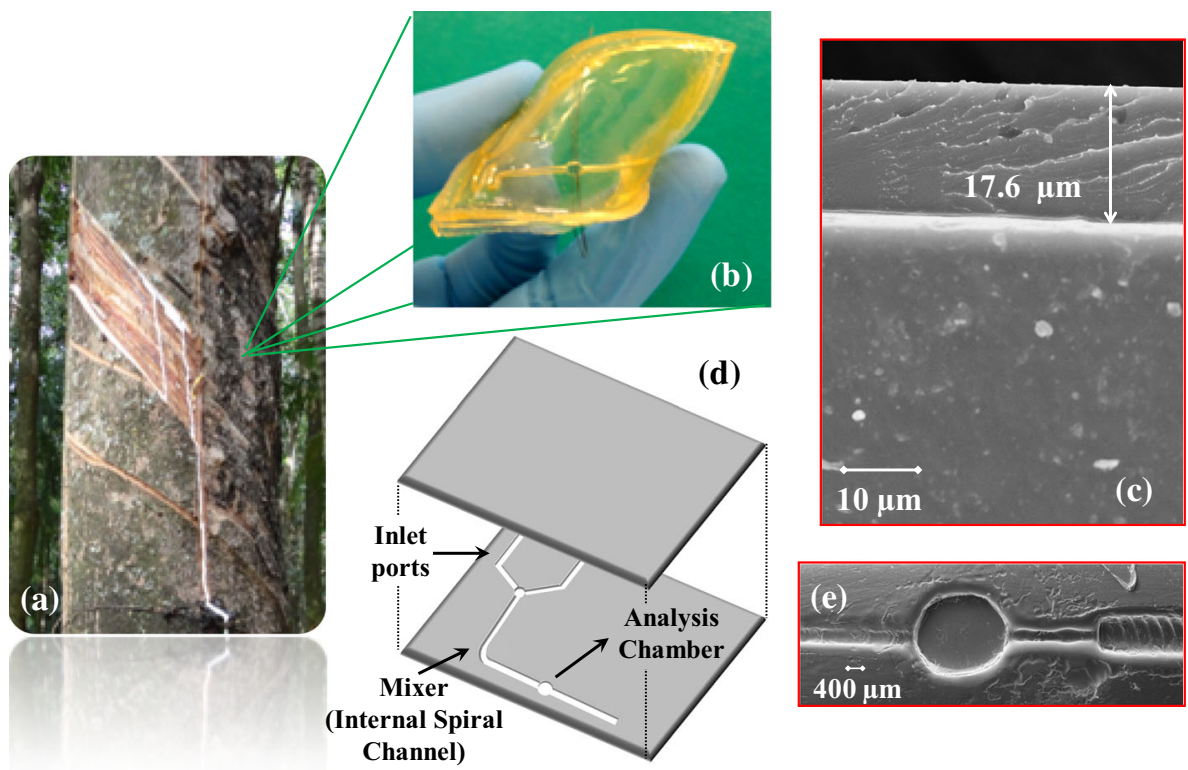

(a)

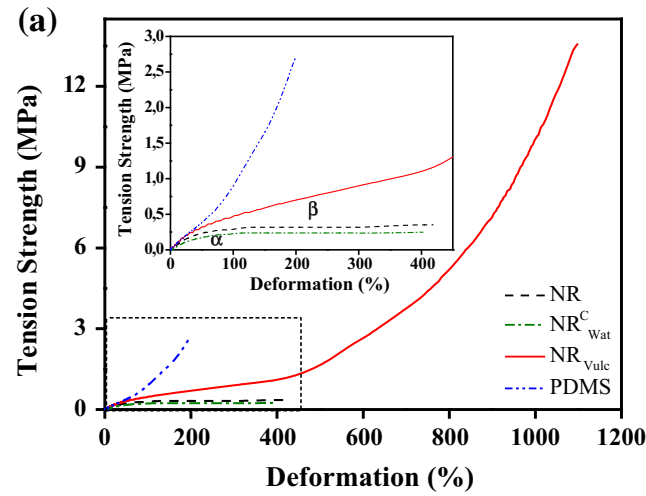

Fig. 2 Stress versus strain mechanical tests comparing the properties of natural rubber (NR), natural rubber prepared from centrifuged latex $\left(\mathrm{NR}_{\mathrm{Wat}}^{\mathrm{C}}\right)$, vulcanized natural rubber $\left(\mathrm{NR}_{\mathrm{Vulc}}\right)$, and poly(dimethylsiloxane) (PDMS). (Inset) region of elastic deformation defined by " $\alpha$ " and polymeric chain deformation " $\beta$ " before plastic deformation

$K_{\mathrm{NR}}=1940 \mathrm{MPa}$.

$K_{\mathrm{PDMS}}=2200 \mathrm{MPa}$.

The average rupture tension, breaking deformation, Young's modulus, and Poisson's ratio are presented in Table 1.

The NR membrane presents an average tension and breaking deformation of $0.37 \mathrm{MPa}$ and $452.5 \%$, respectively. The intensity of the tension/deformation supported by NR before the rupture tension enables the utilization of the polymer as a platform for microfluidic stretchable devices. Soft elastomers, such as Ecoflex (silicone polymer), are an important strategy in the development of microfluidic devices that require stretchability higher than that of the commonly used PDMS [31].

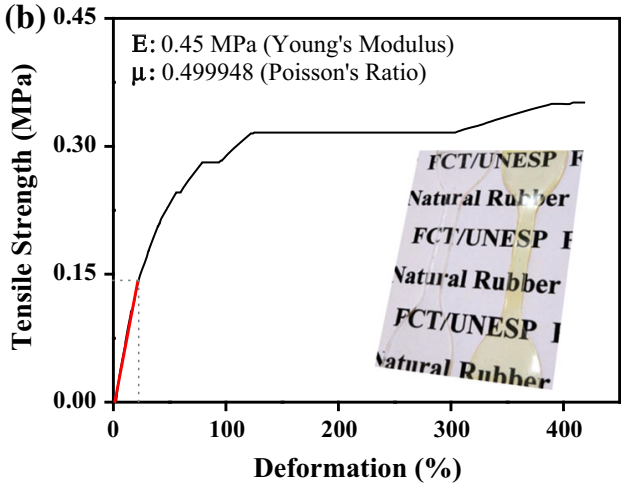

region (b) Detail of the linear highlighted region (NR membrane). Samples were prepared according to ASTM D412 (Photo natural rubber and PDMS membrane samples presented to compare the transparency of membranes)

The centrifugation process of NR decreases both the rupture tension and the breaking deformation to $0.26 \mathrm{MPa}$ and $420.6 \%$, respectively. The thermal treatment (annealing) of natural rubber latex generated interlacement or natural crosslinking between the polymeric chain, which is mainly responsible for the strength resistance. However, the centrifugation process causes the rubber phase (solid) to agglomerate, because it is not totally dissolved in water (solvent), which hinders the crosslink formation. The use of water is suitable to decrease the generation of residues or damage caused by organic solvents.

Vulcanization is an advantageous process for improving the mechanical properties of rubber compared to NR; the rupture tension and deformation increased to $14.0 \mathrm{MPa}$ and 
Table 1 Results of average deformation, breaking tension, Young's modulus, and Poisson's ratio, as calculated from Fig. 2

\begin{tabular}{lclll}
\hline Samples & Average deformation $(\%)$ & Tension at break (MPa) & Young's Modulus (MPa) & Poisson's ratio \\
\hline NR $_{\text {Wat }}^{\mathrm{C}}$ & $420.6 \pm 32$ & $0.26 \pm 0.03$ & 0.4499 & 0.499961 \\
NR & $452.5 \pm 41$ & $0.37 \pm 0.07$ & 0.6035 & 0.499948 \\
NR $_{\text {Vulc. }}$ & $1149.7 \pm 62$ & $14.0 \pm 0.76$ & 0.7884 & 0.499932 \\
PDMS & $200.1 \pm 32$ & $2.73 \pm 0.75$ & 0.8495 & 0.499935 \\
\hline
\end{tabular}

Comparison of properties of $\mathrm{NR}, \mathrm{NR}_{\mathrm{Wat}}^{\mathrm{C}}$, $\mathrm{NR}_{\mathrm{Vulc}}$ and PDMS

$1149.7 \%$, respectively. Moreover, the latex pre-vulcanization process allows the crosslink formation to be performed at lower temperatures and shorter times compared to the typical vulcanization process, which improves the chemical resistance of the rubber, which is important when it is implemented as a device platform material.

The PDMS membranes reached the rupture tension and deformation at $2.73 \mathrm{MPa}$ and $200 \%$, respectively. These values are higher than those obtained for the $\mathrm{NR}$ and $\mathrm{NR}_{\mathrm{W} \text { at }}^{\mathrm{C}}$ membranes but lower than those of $\mathrm{NR}_{\mathrm{Vulc}}$. However, I. D. Johnston et al. reported the mechanical characterization for PDMS, which reached the rupture tension from 3.51 to 7.65 $\mathrm{MPa}$, depending on the curing temperature used [32]. The increase in the rupture tension for $\mathrm{NR}_{\mathrm{Vulc}}$ and PDMS is essential when pressure resistance is required in a microfluidic device.

The improvement in the hardness for $\mathrm{NR}_{\mathrm{Vulc}}$ and PDMS membranes, measured by Young's modulus from 0.45 to 0.79 and $0.85 \mathrm{MPa}$, respectively, are associated with a reduction in the polymeric stretchability. The lower Young's modulus achieved with the $\mathrm{NR}$ and $\mathrm{NR}_{\text {Wat }}^{\mathrm{C}}$ membranes is attractive for materials for microvalve construction, which require specific pressures to switch the internal flow in a microdevice. Moreover, the decrease in the Poisson's ratio from $0.499961\left(\mathrm{NR}_{\mathrm{Wat}}^{\mathrm{C}}\right)$ to 0.499932 $\left(\mathrm{NR}_{\mathrm{Vulc}}\right)$ represents an improvement of the stretching volumetric resistance (lower deformation), which is indispensable to maintain the structure (dimensions) of a microdevice submitted to high flow rates.

\section{Optical properties and surface evaluation}

Figure 3 shows the optical comparative study for the different NR membranes and PDMS. Among the NR membranes, $\mathrm{NR}_{\text {Wat }}^{\mathrm{C}}$ presents the best transmittance in the visible region (around $90 \%$ above $400 \mathrm{~nm}$ ). The centrifuging process has been reported as a clever approach to decrease the amount of protein leached from natural latex [10].

In the case of the NR membrane without centrifugation, the presence of proteins and phospholipids leads to a yellowish color and reduces the transparency [Fig. 1b (inset)] [33-35].
The vulcanization process not only increases the stressstrain resistance of NR but also results in a transmittance around $80 \%$ in the range of 500-800 $\mathrm{nm}$. The shift of the absorption wavelength from 300 to $350 \mathrm{~nm}$ after vulcanization of the NR could be related to the structural modifications (denaturing) of proteins and phospholipids due to the vulcanization agents. The PDMS membrane had exceptional optical properties and was totally transparent in the visible range with a transmittance of $100 \%$ above $300 \mathrm{~nm}$, which is a requirement for the implementation of optical devices.

The covering layer of PVC polymer on the NR surface (NR/PVC) improves chemical resistance without altering the optical properties considerably. The slight decreases of transmittance are attributed to the interface between two different refractive indices (Fig. 3b). In addition, the covering layer prevents the water absorption observed on NR membranes.

The contact angles were measured to evaluate the wettability of the material (Fig. 4). The contact angle directly influences the flow rate into microfluidic devices. The contact angle was measured on the membrane surfaces in contact with the Petri glass during preparation. We previously observed that the surface morphology strongly depends on the side of the membrane, that is, whether it is in contact with the air (superior surface) or in contact with the glass (inferior surface) [27].

The measured contact angles were very similar: $75.1^{\circ}$ for $\mathrm{NR}, 74.5^{\circ}$ for $\mathrm{NR}_{\mathrm{Wat}}^{\mathrm{C}}$, and $75.2^{\circ}$ for $\mathrm{NR}_{\text {Vulc }}$. The PVC covering increases the contact angle, which reaches $83^{\circ}$ due to the decrease in the interaction of the fluid with the surface and the prevention of water absorption by natural rubber. Moreover, the PVC/NR contact angle is smaller than the angle of $101.3^{\circ}$ measured for the PDMS membrane.

Different treatments have been used to modify the PDMS surface wettability for application in biological systems and chemical synthesis. For instance, Tan and co-workers [36] have carried out oxygen plasma treatment to reduce the hydrophobic properties of PDMS polymer and achieved a contact angle between $50^{\circ}$ and $60^{\circ}$. In fact, no significant increases in the contact angle were noticed as a result of the PVC covering over the NR surface, which is a concern for alternative polymeric devices. 
Fig. 3 a UV-Vis spectroscopy comparing the transmittance of $\mathrm{NR}, \mathrm{NR}_{\mathrm{Wat}}^{\mathrm{C}}$, $\mathrm{NR}_{\text {Vulc }}$ and PDMS with a scan rate of $400 \mathrm{~nm} \mathrm{~min}^{-1}$. b Comparison of the optical properties of natural rubber and NR/PVC membranes
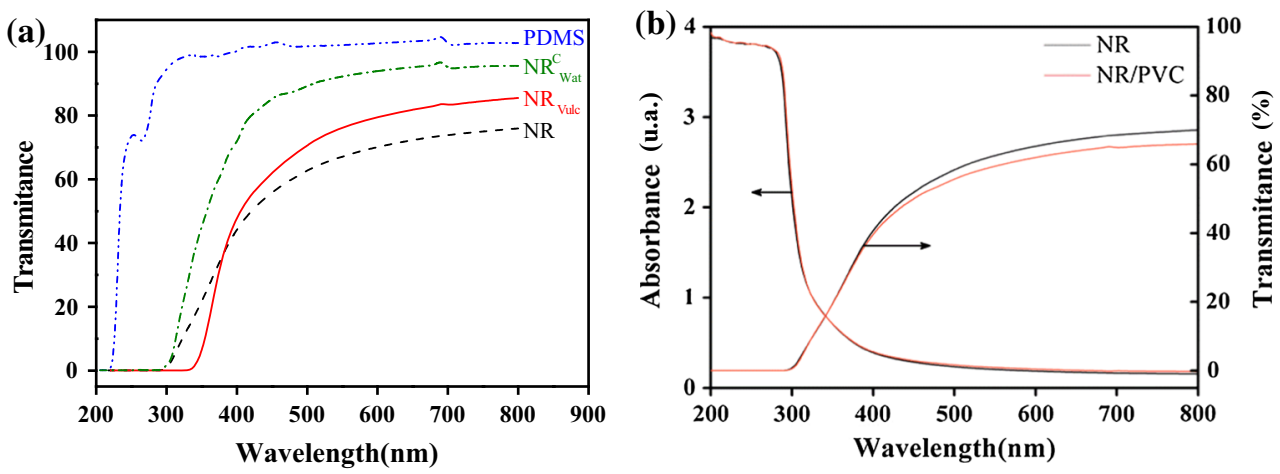

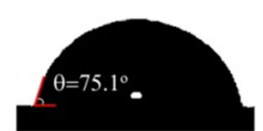

NR

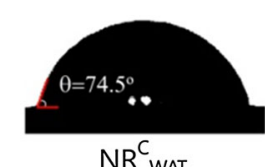

$N R^{C}$ WAT

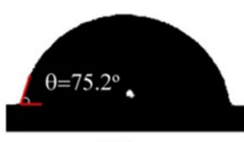

NR vULC
NR/PVC

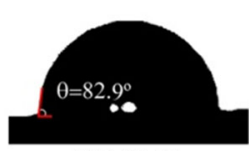

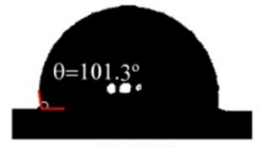

PDMS
Fig. 4 Static contact angle (sessile droplet) measurements performed using distilled and deionized water as the test liquid with a nominal droplet volume of $3.0 \mu \mathrm{L}$ to compare the surface properties of NR, $\mathrm{NR}_{\text {Wat }}^{\mathrm{C}}, \mathrm{NR}_{\text {Vulc }}$, and PDMS

\section{Leached compounds from natural rubber}

The challenge for the use of NR membranes involves the leaching behavior when in contact with fluids. Herein, we evaluate the released compounds and the efficiency of the PVC covering layer to prevent leaching.

In order to evaluate the compounds leached from NR membranes, the $\mathrm{NR}, \mathrm{NR}_{\mathrm{Wat}}^{\mathrm{C}}$, and $\mathrm{NR}_{\text {Vulc }}$ samples were immersed in water at $40{ }^{\circ} \mathrm{C}$ for $5 \mathrm{~h}$, as described in the Materials and Methods (Fig. 5). These experiments are fundamental to define the range of applicability of microfluidic devices.

An absorption band is observed around $264 \mathrm{~nm}$ for the solution leached from Ls-NR, which could be associated with organic compounds present in the latex, including proteins, phospholipids, and amino acids [37] The high concentration of organic compounds is attributed to the liquid phase or Serum $\mathrm{C}$ from latex, which contains proteins, amino acids, carbohydrates, lipids, and nucleic acids (mainly associated with protein composition), which are generally called non-rubber components $[38,39]$.

The absorption band of Ls-NR (264 nm) shifts to $275 \mathrm{~nm}$ for Ls-NR $\mathrm{Wat}_{\mathrm{W}}^{\mathrm{C}}$ and Ls-NR $\mathrm{Vulc}_{\mathrm{v}}$, and the appearance of a new band around $226 \mathrm{~nm}$ is observed (Fig. 5a (inset)).

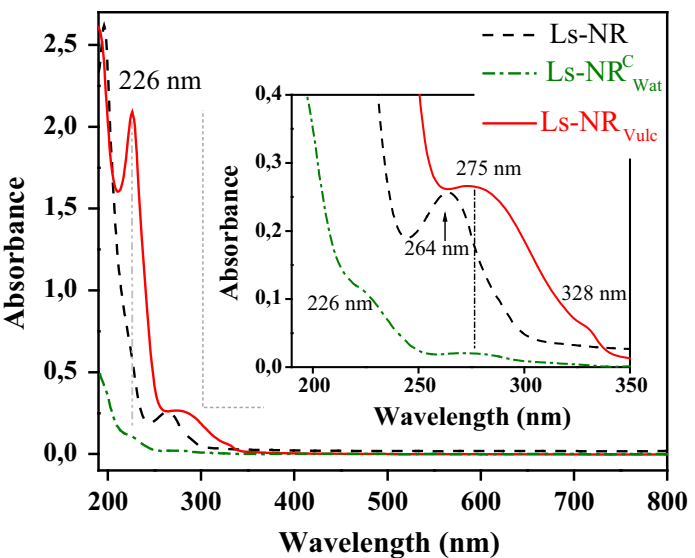

Fig. 5 UV-Vis spectroscopy to evaluate the liquid phase (water) from tests of leaching compounds from natural rubber (Ls-NR), natural rubber prepared from centrifuged latex $\left(\mathrm{Ls}-\mathrm{NR}_{\mathrm{Wat}}^{\mathrm{C}}\right)$, and vulcanized natural rubber $\left(\mathrm{Ls}-\mathrm{NR}_{\mathrm{Vulc}}\right)$. The experiment was carried out at $40{ }^{\circ} \mathrm{C}$ for $5 \mathrm{~h}$. The solutions were evaluated after removing the immersed membranes

The amount of leached compounds is higher for $\mathrm{NR}_{\mathrm{Vulc}}$, which is attributed to the higher water content and greater porosity, which may enhance the amount of proteins migrating to the surface and consequently the amount of protein released into solution when immersed in water [10, 40]. The porosity of natural rubber membranes can be observed in the AFM images in Fig. 6. Two groups of micropore sizes are observed around 105.7 and $313.7 \mathrm{~nm}$. These porous surfaces can aid the leaching of the nonrubber compounds and the absorption of water by NR membranes. Moreover, the release of amides from polymeric chains could be related to the hydrolysis process of polymers in water [41, 42], which could be associated with the $\alpha$-terminal phospholipid groups present on the NR chain [43] The leaching compounds from the NR membrane are strictly decreased after the centrifuging process $\left(\mathrm{NR}_{\mathrm{Wat}}^{\mathrm{C}}\right)$ i.e., the centrifuging process decreases the amount of protein compounds in latex. 
(a)

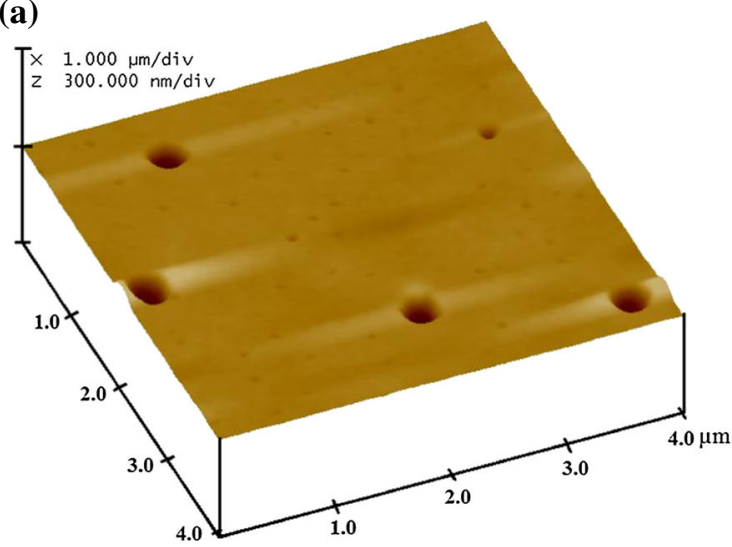

(c)

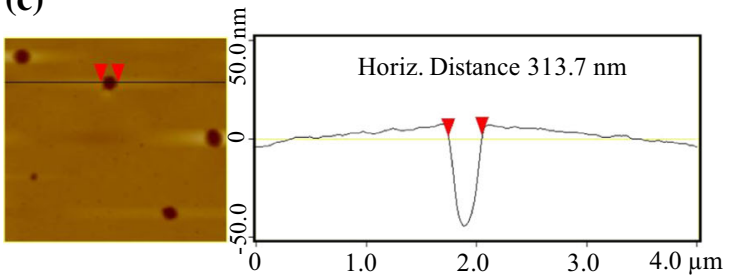

Fig. 6 Atomic force microscopy to evaluate the natural rubber (NR) surface. a Scale of $4.0 \mu \mathrm{m}^{2}$, b scale of $2.0 \mu \mathrm{m}^{2}$, and $\mathbf{c}$ pores measured with widths around $313.7 \mathrm{~nm}$ and $\mathbf{d} 105.7 \mathrm{~nm}$. The AFM images were

FT-IR/ATR spectroscopy was implemented to investigate the compounds leached from $\mathrm{NR}, \mathrm{NR}_{\mathrm{Vulc}}$, and $\mathrm{NR}_{\mathrm{Wat}}^{\mathrm{C}}$ membranes. The aqueous solutions obtained by immersion of the membranes were previously lyophilized. The results are shown in Fig. 7. The attribution of peaks related to poly-1,4-cis-isoprene compounds (the main chain of the NR membranes) is presented in Table S2 (Supporting Information) [39, 44, 45].

The essential results from FT-IR spectroscopy are relative to the shift of the peaks associated with amide compounds and terminal groups related to $-\mathrm{CH}_{3}$ - compounds $\left(1394 \mathrm{~cm}^{-1}\right)$. The peak at $1580 \mathrm{~cm}^{-1}$ was attributed to the stretching $(\mathrm{C}-\mathrm{N}) /$ deformation $(\mathrm{N}-\mathrm{H})$ and the peak at $3261 \mathrm{~cm}^{-1}$ attributed to the symmetric stretching of N-H obtained for Ls-NR shifted to 1569 and $3294 \mathrm{~cm}^{-1}$ for Ls-NR $\mathrm{N}_{\mathrm{Wat}}^{\mathrm{C}}$ and shifted to 1559 and $3292 \mathrm{~cm}^{-1}$ for $\mathrm{NR}_{\mathrm{Vulc}}$.

The shift of the wavenumbers can be related to denaturation or structural modifications of the compounds [46], which corroborate the structural modification of proteins observed by the modification of the absorption bands according to UV-Vis spectroscopy.

The leaching solutions from Ls-NR, Ls-NR $\mathrm{Wat}_{\mathrm{W}}^{\mathrm{C}}$, and Ls$\mathrm{NR}_{\text {Vulc }}$ were also evaluated using atomic mass spectroscopy to identify the released inorganic compounds, as shown in Table 2 . The elements were evaluated by relying on the compounds identified in the elementary chemistry study of latex reported by E. A. Hwee [37]. They reported (b)

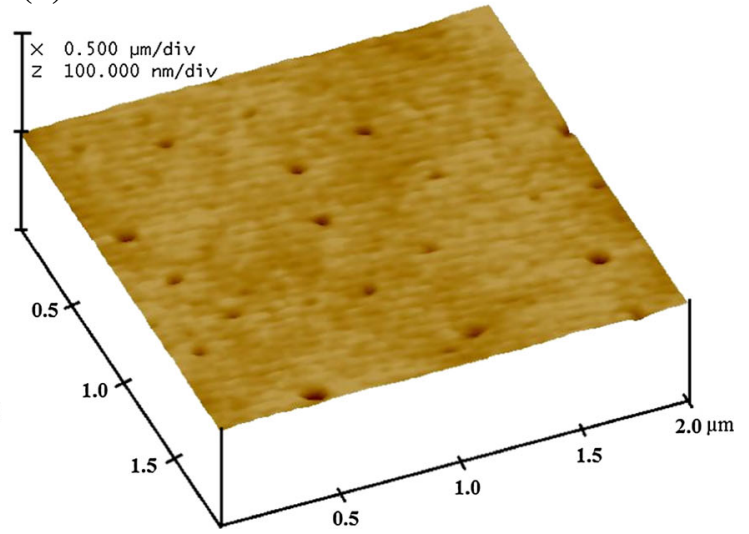

(d)

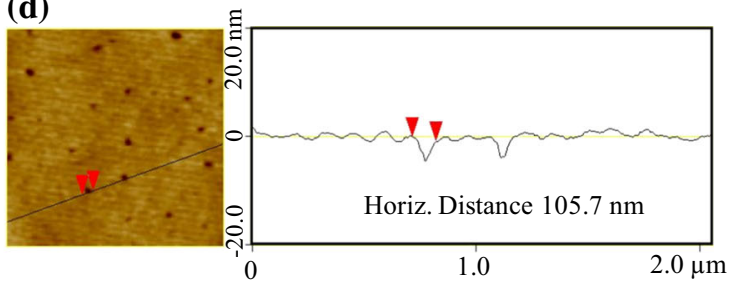

collected using a Digital Instrument model Nanoscope IV, with a silicon nitride tip and a spring constant of $0.12 \mathrm{~N} / \mathrm{m}$ in contact mode

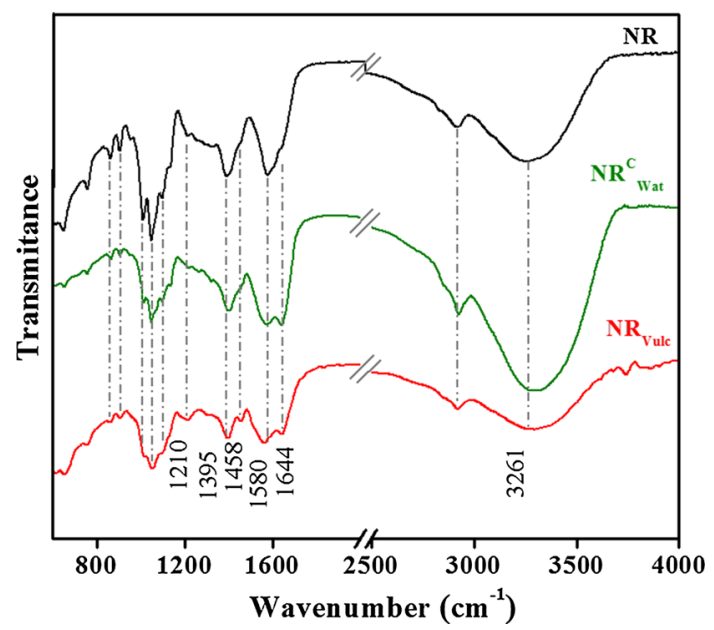

Fig. 7 FT-IR/ATR spectroscopy to evaluate the solid-leached compounds obtained from the liquid phase (water) from tests of Ls-NR, Ls- $\mathrm{NR}_{\mathrm{Wat}}^{\mathrm{C}}$, and Ls-NR $\mathrm{Vulc}_{\mathrm{V}}$ after lyophilization. The experiment to obtain the leached compounds was carried out at $40{ }^{\circ} \mathrm{C}$ for $5 \mathrm{~h}$

that the inorganic concentration of latex compounds is influenced by weather, soil conditions, clonal origin, etc.

The NR membranes leached compounds such as potassium at a level of $0.865 \mathrm{mg} \mathrm{L}^{-1}$ and sodium at a level of $2.5 \mathrm{mg} \mathrm{L}^{-1}$, which are mostly associated with the soil composition and agricultural inputs implemented in latex production. The concentrations of potassium and calcium 
Table 2 Atomic mass spectroscopy to evaluate the inorganic components in the solutions containing compounds leached from Ls-NR, Ls-NR $\mathrm{Wat}_{\mathrm{Wat}}^{\mathrm{C}}$, and Ls-NR $\mathrm{Vulc}$

\begin{tabular}{llll}
\hline Reference SMEWW $213030 \mathrm{E}$ & \multicolumn{3}{l}{ Results $\left(\mathrm{mg} \mathrm{L}^{-1}\right)$} \\
\hline Element & $\mathrm{L}_{\mathrm{S}}-\mathrm{NR}$ & $\mathrm{L}_{\mathrm{S}}-\mathrm{NR}_{\text {Wat }}$ & $\mathrm{L}_{\mathrm{S}}-\mathrm{NR}_{\text {Vulc }}$ \\
Phosphor & $\mathrm{DL}$ & $\mathrm{DL}$ & $\mathrm{DL}$ \\
Sulfur & - & - & $\mathrm{DL}$ \\
Potassium & 0.865 & $\mathrm{DL}$ & 5.289 \\
Calcium & $\mathrm{DL}$ & 0.200 & $\mathrm{DL}$ \\
Manganese & $\mathrm{DL}$ & $\mathrm{DL}$ & $\mathrm{DL}$ \\
Magnesium & $\mathrm{DL}$ & 0.058 & 0.6975 \\
Iron & $\mathrm{DL}$ & 0.043 & $\mathrm{DL}$ \\
Zinc & - & - & $\mathrm{DL}$ \\
Sodium & 2.5 & $\mathrm{DL}$ & 3.1 \\
\hline
\end{tabular}

$D L$ under detection limit

increased considerably for Ls-NR $\mathrm{Vulc}_{\mathrm{c}}$, reaching 5.289 and $3.1 \mathrm{mg} \mathrm{L}^{-1}$, respectively, which is attributed to the composition of the vulcanization agents used on the latex. There were similar increases in the concentration of magnesium for $\mathrm{Ls}_{-} \mathrm{NR}_{\text {Vulc }}$, measured at $0.6975 \mathrm{mg} \mathrm{L}^{-1}$. The zinc oxide and sulfur concentrations were measured above the limits of detection from the mass spectrometer, which are important factors that prove the high efficiency of the vulcanization process implemented.

The concentration of magnesium measured for Ls-NR $\mathrm{Wat}_{\mathrm{C}}^{\mathrm{C}}$ is around $0.058 \mathrm{mg} \mathrm{L}^{-1}$, that of calcium is $0.200 \mathrm{mg} \mathrm{L}^{-1}$, and that of iron is $0.043 \mathrm{mg} \mathrm{L}^{-1}$, which can be attributed to the centrifuging process. Centrifuging is associated with the separation of different molecular weights, thus decreasing the amounts of sodium and potassium when compared to the compounds leached from NR membranes.

The addition of the PVC covering layer over the NR membrane is show in Fig. 8. The evaluation of the liquid phase was carried out after immersion in water for 3 and $5 \mathrm{~h}\left(\mathrm{~S}_{\mathrm{L}}-\mathrm{NR} / \mathrm{PVC}\right)$ at 40 and $25^{\circ} \mathrm{C}$. (Experiments were carried out after removing the membranes; evaluation considered only the water medium).

The quantity of leaching compounds increased with the immersion time, as expected. In addition, the leaching effect is higher at $40{ }^{\circ} \mathrm{C}$, which can be attributed to the dilation of the porous surface of PVC. Because most applications of rubber-based microfluidic devices are at environmental temperatures, the result obtained at $25{ }^{\circ} \mathrm{C}$ for $5 \mathrm{~h}$ is very promising and significant (inset of Fig. 8). The PVC covering layer provides an impermeable surface that contributes to reductions of water absorption and the release of compounds from the NR membrane.

In another approach, F. W. Perrella et al. [10] reported a water-washing method to decrease the non-rubber

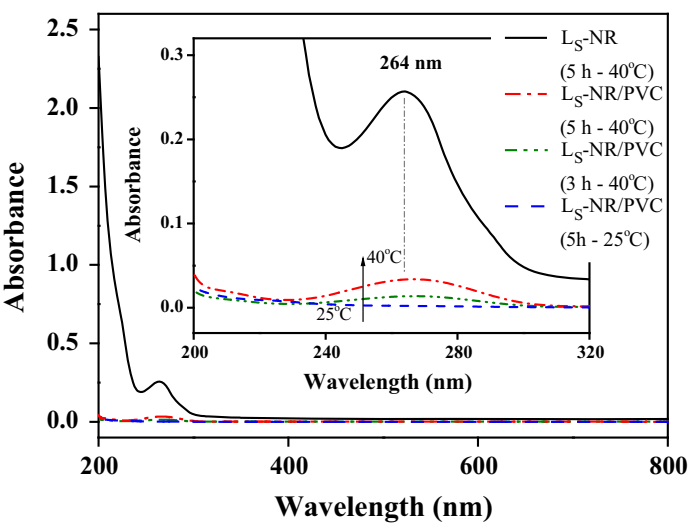

Fig. 8 UV-Vis spectroscopy evaluation of the liquid phase (water) from tests of leaching compounds from NR membranes covered with PVC (Ls-NR/PVC). The experiment was carried out at 25 and $40{ }^{\circ} \mathrm{C}$ for 3 and $5 \mathrm{~h}$. The solutions were evaluated after removing the membranes

compounds in NR. Here, we carried out the washing tests using similar parameters $\left(40{ }^{\circ} \mathrm{C}\right.$ for $\left.5 \mathrm{~h}\right)$ followed by a thermal treatment at $65{ }^{\circ} \mathrm{C}$ until the entire rubber surface dried. These procedures were carried out for four cycles (Fig. 9).

After the first cycle, the amount of non-rubber leached compounds was significantly reduced. The decrease in the amount of leached compounds reached the maximum limit after cycle III. However, the water-washing cycles do not prevent the absorption of water by NR membranes. This challenge was overcome using the PVC covering, and the water-washing treatment was a complement to improve the NR properties.

Nevertheless, information on the compounds leached from rubber membranes is essential for the implementation of lab-on-a-chip devices. These compounds will not interfere in the device measurements because of continuous flow, i.e., the concentrations inside the device may reach insignificant values. Moreover, the use of a polymeric layer covering of PVC prevents the leaching of compounds from rubbers when implemented during microfluidic device preparation.

\section{Conclusion}

In this paper, we report the optimization of the mechanical, optical, and structural properties of NR membranes, which were recently introduced to rubber-based microfluidic devices (NRMDs). The vulcanization process was evaluated as a methodology for increasing the mechanical resistance without considerable interference to the optical properties of rubber. The centrifuging process is essential for improvements of the optical properties (increase of the 


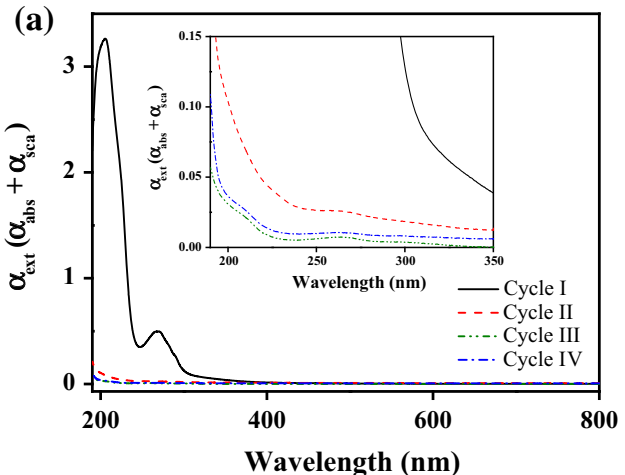

Fig. 9 a UV-Vis spectroscopy to evaluate the cycles of leaching compounds from natural rubber carried out by immersing the rubber membranes in water at $40{ }^{\circ} \mathrm{C}$ for $5 \mathrm{~h}$. After the leaching process, the

percent transmittance) and decreases of the amount of nonrubber compounds leached from NR membranes in liquid environments. The PVC covering layer proposed here prevented both the rubber water absorption and the leaching of non-rubber components without a considerable increase of the surface contact angle. Essentially, the NR membranes can handle the process of covering with polymers, which is interesting for improving the range of polymeric applications. Finally, herein we report different approaches (vulcanization, centrifuging, PVC covering, and water washing) to improve the properties of natural rubber-based microfluidic devices, which are an alternative, flexible, and low-cost material for microfluidic technology.

Acknowledgements The authors are grateful to the Brazilian agencies for financial supports of their research activities: FAPESP (F. C. Cabrera-Doctoral Fellowship number 2011/23362-0; F. N. Crespilho-project numbers 2013/14262-7 and 2013/04663-4; and A. E. Job-project number 2013/01066-9), CNPq (F. N. Crespilho project numbers 306106/2013-2 and 478525/2013-3), and the INEO and Nanomedicine Networks (NanoBio-Net and NanoBioMed-Brazil, CAPES). The authors are also grateful to Prof. Dr. Ricardo F. Aroca and Windsor University for the AFM microscopy analysis.

\section{References}

1. Scherillo G, Lavorgna M, Buonocore GG, Zhan YH, Xia HS, Mensitieri G, Ambrosio L (2014) Tailoring assembly of reduced graphene oxide nanosheets to control gas barrier properties of natural rubber nanocomposites. ACS Appl Mater Interfaces 6:2230-2234

2. Lin T, Ma S, Lu Y, Guo B (2014) New design of shape memory polymers based on natural rubber crosslinked via oxa-Michael reaction. ACS Appl Mater Interfaces 6:5695-5703

3. Quitmann D, Gushterov N, Sadowski G, Katzenberg F, Tiller JC (2014) Environmental memory of polymer networks under stress. Adv Mater 26:3441-3444

4. Quitmann D, Gushterov N, Sadowski G, Katzenberg F, Tiller JC (2013) Solvent-sensitive reversible stress-response of shape memory natural rubber. Appl Mater Interfaces 5:3504-3507

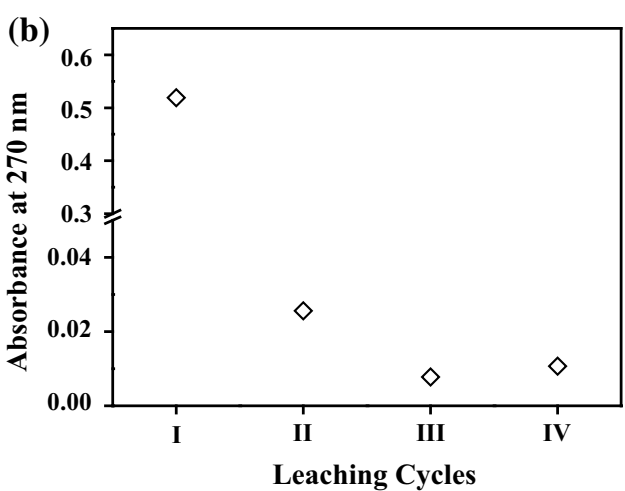

membranes are dried at $65{ }^{\circ} \mathrm{C}$. These procedures were implemented for each cycle. b Evaluation of the absorbance band related to nonrubber compounds at $270 \mathrm{~nm}$ for each of the four cycles

5. Qiu T, Zeng Q, Ao N (2014) Preparation and characterization of chlorinated nature rubber (CNR) based polymeric quaternary phosphonium salt bactericide. Mater Lett 122:13-16

6. Zhang Y, Xue X, Zhang Z, Liu Y, Li G (2014) Morphology and antibacterial properties of natural rubber composites based on biosynthesized nanosilver. J Appl Polym Sci. doi:10.1002/APP. 40746

7. Cottinet P-J, Guyomar D, Galineau J, Sebald G (2012) Electrothermo-elastomers for artificial muscles. Sens Actuators A 180:105-112

8. Flory PJ (1944) Network structure and the elastic properties of vulcanized rubber. Chem Rev 35:51-75. doi:10.1021/cr60110a002

9. Hasan A, Rochmadi SH, Honggokusumo S (2013) Vulcanization kinetics of natural rubber based on free sulfur determination. Indones J Chem 13:21-27

10. Perrella FW, Gaspari AA (2002) Natural rubber latex protein reduction with an emphasis on enzyme treatment. Methods 27:77-86

11. Meade BJ, Weissman DN, Beezhold DH (2002) Latex allergy: past and present. Int Immunopharmacol 2:225-238

12. Knop KJ, Bridts CH, Verweij MM, Hagendores MM, de Clerck LS, Stevens WJ, Ebo DG (2010) Component-resolved allergy diagnosis by microarray: potential, pitfalls, and prospects. Adv Clin Chem 50:87-101

13. Cabrera FC, Souza JCP, Job AE, Crespilho FN (2014) Naturalrubber-based flexible microfluidic device. RSC Adv 4:35467-35475

14. Cabrera FC, Melo AFAA, Souza JCP, Job AE, Crespilho FN (2015) A flexible lab-on-a-chip for the synthesis and magnetic separation of magnetite decorated with gold nanoparticles. Lab Chip 15:1835-1841

15. Vasdekis AE, Wilkins MJ, Grate JW, Kelly RT, Konopka AE, Xantheas SS, Chang T-M (2014) Solvent immersion imprint lithography. Lab Chip 14:2072-2080

16. Ahn CH, Choi J-W, Beaucage G, Nevin JH, Lee J-B, Puntambekar A, Lee JY (2004) Disposable smart lab on a chip for pointof-care clinical diagnostics. Proc IEEE 92:154-173

17. Sakamoto H, Hatsuda R, Miyamura K, Sugiyama S (2012) Plasma separation PMMA device driven by capillary force controlling surface wettabilitys. Micro Nano Lett 7:64-67

18. Chhina SK, Perez CF, Parameswaran M (2012) Microfluidic system to detect DNA amplicons using agglutination technique. J Micromech Microeng 22:1-8

19. Moriuchi T, Sumida S, Furuya A, Morishima K, Furukawa Y (2009) Direct photosynthetic/metabolic biofuel cell for mobile use. Int J Precis Eng Manuf 10:75-78 
20. Song W, Vasdekis AE, Psaltis D (2012) Elastomer based tunable optofluidic devices. Lab Chip 12:3590-3597

21. Alvankarian J, Majlis BY (2012) A new UV-curing elastomeric substrate for rapid prototyping of microfluidic devices. J Micromech Microeng 22:1-15

22. Foudeh AM, Didar TF, Veresa T, Tabrizian M (2012) Microfluidic designs and techniques using lab-on-a-chip devices for pathogen detection for point-of-care diagnostics. Lab Chip 12:3249-3266

23. Liu F, Nordin AN, Li F, Voiculescu I (2014) A lab-on-chip cellbased biosensor for label-free sensing of water toxicants. Lab Chip 14:1270-1280

24. Chiriacó MS, Primiceri E, D́Amone E, Ionescu RE, Rinaldi R, Maruccio G (2011) EIS microfluidic chips for flow immunoassay and ultrasensitive cholera toxin detection. Lab Chip 11:658-663

25. Kim DN, Lee Y, Koh W-G (2009) Fabrication of microfluidic devices incorporating bead-based reaction and microarray-based detection system for enzymatic assay. Sensors and Actuators B 137:305-312

26. Zheng W, Jiang B, Wang D, Zhang W, Wang Z, Jiang X (2012) A microfluidic flow-stretch chip for investigating blood vessel biomechanics. Lab Chip 12:3441-3450

27. Faita FL, Dotto MER, França LG, Cabrera FC, Job AE, Bechtold IH (2014) Characterization of natural rubber membranes using scaling laws analysis. Eur Polym J 50:249-254

28. ASTM D 412 (2013) Test methods for vulcanized rubber and thermoplastic elastomers-tension. ASTM international

29. Mrué F, Netto JC, Ceneviva R, Lachat JJ, Thomazini JA, Tambelini $\mathrm{H}$ (2004) Evaluation of the biocompatibility of a new biomembrane. Mater Res 7:277-283

30. Ferreira M, Mendonça RJ, Coutinho-Netto J, Mulato M (2009) Angiogenic properties of natural rubber latex biomembranes and the serum fraction of hevea brasiliensis. Braz J Phys 39:564-569

31. Kubo M, Li X, Kim C, Hashimoto M, Wiley BJ, Ham D, Whitesides GM (2010) Stretchable microfluidic radiofrequency antennas. Adv Mater 22:2749-2752

32. Johnston ID, McCluskey DK, Tan CKL, Tracey MC (2014) Mechanical characterization of bulk sylgard 184 for microfluidics and microengineering. J Micromech Microeng 24:1-7

33. Leela E, Muhamed AP (2006) Assessment of biodeterioration of rubber wood exposed to field conditions. Int Biodeterior Biodegradation 57:31-36
34. Blackley DC (1997) Polymers latices, vol 2. Chapman \& Hall, Glasgow

35. Sethuraj MR, Mathew NM (1992) Natural rubber. biology, cultivation and tehchnology. Elsevier Science, Netherlands

36. Say HT, Nguyen N-T, Chua YC, Kang TG (2010) Oxygen plasma treatment for reducing hydrophobicity of a sealed polydimethylsiloxane microchannel. Biomicrofluidics 4:032204$1-032204-8$

37. Hwee EA (2014) (Chapter 3) non-rubbers and abnormal groups in natural rubber. In: Thomas S, Chan $\mathrm{CH}$, Pothen LA, Rajisha KR, Hanna JM (eds) Natural rubber materials, vol. 1: blends and IPNs, vol 7., RSC polymer chemistry seriesRSC Publishing, Cambridge

38. Li S-D, Yu H-P, Zhu C-S, Li P-S (2000) Study on thermal degradation of sol and gel of natural rubber. J Appl Polym Sci 75:1339-1344

39. Agostini DLS, Constantino CJL, Job AE (2008) Thermal degradation of both latex and latex cast films forming membranes combined TG/FTIR investigation. J Therm Anal Calorim 91:703-707

40. Yeang HY, Sunderasan E, Ghazali HM (1995) Latex allergy studies: extraction of natural rubber latex proteins with reference to film thickness, latex DRC and protein migration behaviour. J Nat Rubber Res 10:46-62

41. Seager SL, Slabaugh MR (1999) Organic and biochemistry for today, 4th edn. Brooks/Cole - Thomson Learning, Belmont, USA

42. De Paoli, M.A. Degradação e Estabilização de Polímeros, Ed 2. João Carlos de Andrade (editor). 2008

43. Amnuaypornsri S, Sakdapipanich J, Tanaka Y (2010) Highly purified natural rubber by saponificaion of latex: analysis of green and cured properties. J Appl Polym Sci 118:3524-3531

44. Nallasamy P, Mohan S (2004) Vibrational Spectra of Cis-1,4Polyisoprene. The Arab J Sci Eng 29:17-26

45. Healey AM, Hendra PJ, West YD (1996) A fourier-transform Raman study of the strain-induced crystallization and cold crystallization of natural rubber. Polymer 37:4009-4024

46. Kong J, Yu S (2007) Fourier transform infrared spectroscopic analysis of protein secondary structures. Acta Biochim Biophys Sin 39:549-559 